ISSUES IN UNDERGRADUATE EDUCATION

\title{
Impressions of nursing before exposure to the field
}

\author{
Frances O'Brien RGN, DNS, BNS, RNT, MA \\ Lecturer, School of Nursing and Midwifery, Trinity College Dublin, Dublin, Ireland \\ Mary Mooney RGN, RM, RNT, HDip, MSc \\ Lecturer, School of Nursing and Midwifery, Trinity College Dublin, Dublin, Ireland \\ Michele Glacken PhD, PGDip (Adv Nurs), BSc, RM, RGN \\ Head of Department of Nursing \& Health Studies, St Angela's College, Sligo, Republic of Ireland
}

Submitted for publication: 9 February 2007

Accepted for publication: 7 September 2007

\section{Correspondence:}

Frances O'Brien

School of Nursing and Midwifery

Trinity College Dublin

24 D’Olier Street

Dublin 2

Ireland

Telephone: 3531896 2692/3107

E-mail: obrienfr@tcd.ie
O'BRIEN F, MOONEY M \& GLACKEN M (2008) Journal of Clinical Nursing 17, 1843-1850

\section{Impressions of nursing before exposure to the field}

Aims and objectives. This paper reports on non-mature general nursing students' perceptions of nursing as a career prior to their first clinical placement.

Background. It is widely recognised that the first clinical practice experience serves a dual role, that of validating students' choice of career and shaping their perceptions of nursing. This study sought to explore 23 first year non-mature ( $<23$ years) nursing students' perceptions of nursing as a career prior to their first clinical exposure. The students accessed the programme via two different modes of recruitment.

Method. This qualitative descriptive study used focus group interviews as a means of data collection. Interviews were held within 10 weeks of entry into nursing. Data were analysed using the five stages of framework analysis. Ethical approval was obtained.

Results. Mode of recruitment did not influence students' perceptions of nursing. The students unanimously identified caring as the essence of nursing. They also acknowledged the role of the media in shaping theirs and society's perception of nursing. Male students expressed concern regarding the negative connotations associated with their career choice. Student participants could not appreciate the totality of the curriculum content at this stage of their course.

Conclusions. Caring remains the essence of nursing. Educators need to take cognisance of first year students' abilities to appreciate the link between theory and practice. This may be enhanced by the employment of teaching strategies that role-model this link for students. Recruiters must be proactive in addressing the challenges facing males in choosing nursing as a career.

Relevance to clinical practice. An insight into how nursing students perceive nursing prior to their first clinical placement is important for clinicians. This information is valuable in terms of providing registered nurses with an understanding of the students' perspective and the associated supports required by nursing students on first clinical placements. 
Key words: caring, first clinical placement, nurses, nursing, nursing students, perceptions of nursing

\section{Introduction and background to study}

Recent years have seen a decline in the recruitment of students into general nursing in Ireland (Wells \& McElwee 2000). There has also been an increase in attrition rates and together, these factors contribute towards the imbalance between supply and demand. These issues cause concern for stakeholders within the health service (Kennedy 1999). The Commission on Nursing (1998, p. 83) recommended 'that admission to the nursing profession be on the basis of the attainment of a specified leaving certificate standard plus an interview'. This recommendation was based on consultations with members of the nursing profession among others. However, this proposal was not legislative and only one School of Nursing in Ireland chose to adopt the recommendation.

Within the Irish context, there are two principal methods by which those interested in nursing as a career can gain a place on an undergraduate nursing registration programme. Thirteen Higher Education Institutions (University or Institutes of Technology) offer undergraduate nursing registration programmes in various divisions (General/Intellectual Disability/ Psychiatric/Children's \& General/Midwifery). The Department of Health predetermines the number of places that each of the Higher Education Institutions (HEIs) is allowed to offer. All applicants apply through the Central Applications Office (CAO). The Higher Education Institutions in the Republic of Ireland have delegated to the CAO the task of processing centrally, applications to their first year undergraduate courses, with the participating institutions retaining the function of making decisions on admissions. Places are allocated until exhausted to non-mature $(<23$ years) schoolleaving students who achieve a certain standard on the recognised national final school examination (Leaving Certificate). No selection interview is required. Mature applicants ( $>23$ years) also apply to the CAO but in addition must undertake a written examination and selection interview. This process is managed by the Nursing Careers Centre. However, an anomaly exists whereby in one HEI, non-mature applicants are requested to attend a selection interview and apply by the normal route $(\mathrm{CAO})$ if they wish to be associated with a particular healthcare provider. This anomaly is historical in nature. Students who elect to undertake the selection interview and are successful in gaining a place receive a nominal grant by the healthcare provider. It should be noted that students who do not opt to be recruited by this method are also allocated by the HEI to this healthcare provider for their clinical experiences. This study includes students recruited by both the above methods (CAO \& selection interview and CAO only) to the HEI and associated healthcare partner, which are affected by this anomaly.

It has been suggested that preregistered nurses have a very rudimentary concept of professional identity and a limited awareness of what the nursing course entails (Harvey \& McMurray 1997, Cook et al. 2003). It is, therefore, important to address the issue of selection and recruitment of nursing students so as to enlist those who are highly motivated and therefore less likely to discontinue the course (White et al. 1999, Brodie et al. 2004, Grainger \& Bolan 2006, Hoke 2006, Seago et al. 2006). One of the aims of this paper is to present non-mature general nursing students' perceptions of nursing prior to their first clinical placement. A secondary aim of this paper is to identify whether perceptions of nursing differed between two groups of students who were recruited into nursing by different methods. This study is relevant to the future of nursing education and is pertinent to the maintenance of health and social gain of clients who depend on nursing care within and beyond healthcare institutions.

It is important to ascertain how students perceive nursing, as the decision to pursue a particular career is influenced by one's preconceived ideas of that career. The media and society are recognised as influential factors in the portrayal of the image and work of a nurse and consequently on one's decision to choose nursing as a career (Roper 1976, Kiger 1993, Godfrey 2000, Grainger \& Bolan 2006). It has been suggested that a positive impression of nursing has the potential to attract applicants into the profession while a poor image has a negative impact on recruitment (Andrica 1995, Meier 1999, Beck 2000, Rheaume et al. 2003, Hoke 2006, Seago et al. 2006). Godfrey (2000) observed that the false impression of nursing portrayed by the media contributes towards an increase in attrition rates by nursing students. However, Larsen et al. (2003) considered the media to be less influential than one might expect. Overall, nursing is generally favourably perceived for its ability to provide security of employment and a steady income (Williams et al. 1997, While \& Blackman 1998, Larsen et al. 2003, Seago et al. 2006). In the light of the above, the importance of how nursing is portrayed to potential applicants cannot be underestimated. Therefore, the need to depict a realistic image of nursing is paramount to cull attrition because of an inaccurate impression of nursing. Consequently, recruiters should engage nursing students in the formulation of the image of nursing. 
Studies suggest that nursing is perceived as a job that involves caring, nurturing and teaching, and one which requires strength, patience and compassion (Manninen 1998, While \& Blackman 1998, Spouse 2000, Cook et al. 2003). Nursing has, however, been traditionally associated with feminine characteristics and, as such, is frequently perceived as a woman's job (Manninen 1998). This gender bias in nursing has been raised frequently in the literature (HemsleyBrown \& Foskett 1999, Evans 2004, Yam 2004, Keogh \& O’Lynn 2006, Seago et al. 2006). While both males and females perceive nursing to be a career that necessitates a desire to care for people, there are apparent gender differences in other motivating factors associated with choosing nursing as a career (Rheaume et al. 2003).

More male than female students perceive that nursing involves working with complex technology and consider nursing to offer career potential (Rheaume et al. 2003). May et al. (1991) assert that this is consistent with the public image of nursing, which is linked less with independent decisionmaking than technical skills. The female students studied by Boughn and Lentini (1999) expressed an expectation of empowerment of themselves and others through nursing. These researchers (Boughn \& Lentini 1999) advocate that students be taught that caring for others is not incompatible with caring for one's own basic needs. These basic needs include salary, job security and appropriate working conditions. There is no evidence in the literature to suggest that, to date, this message has been endorsed in either nursing practice or education.

\section{Method}

The study reported in this paper is part of a longitudinal study which is seeking to explore if mode of entry into nursing impacts on a number of key issues such as attrition rate, academic success, clinical competence, perceptions of nursing and professional attitudes of nursing students.

\section{Research aim}

To explore non-mature general nursing students' perceptions of nursing as a career prior to their first clinical placement. A secondary aim of the study reported here was to examine whether these perceptions were different between the two groups who were selected into the nursing profession by different methods.

\section{Research design}

A qualitative descriptive design was deemed most appropriate to fulfil the research aims. Focus group interviews were chosen as the mode of data collection, as it was recognised that they have the advantage of being stimulating, inexpensive and capable of producing the rich data (Streubert Speziale \& Carpenter 2003) required in this study. It was also acknowledged that focus group interviews are suited to students, as they provide a safe environment in which to share their thoughts and feelings about the topic under exploration (Kitzinger 1994), a key principal to conducting an ethically sound study.

\section{Location}

The study took place in the HEI where the students under exploration are registered. Permission to access the population was sought and obtained from the HEI's School Director. An independent gatekeeper from the HEI visited the students and provided them with verbal and written information sheets and consent forms for their consideration. Ten days later, the gatekeeper revisited the students and collected the signed consent forms from those students willing to participate in the interviews. Students were assured that no penalty would arise from withdrawal or non-participation in the study.

\section{Sample}

A non-probability sampling strategy was used. All 54 nonmature (less than 23 years) undergraduate nursing students registered on one HEI's undergraduate nursing registration programme were invited to participate (CAO \& selection interview, $n=28$ vs. CAO only, $n=26$ ). Mature students were excluded from participating because they were not recruited through one of the two methods under exploration. Furthermore, it was recognised that, because of their maturity, they may have had life experiences that involved contact with healthcare prior to commencing the course and this could have potentially influenced the study findings. The achieved sample consisted of 23 students, which constitutes a $43 \%$ response rate (CAO \& selection interview, $n=14$ vs. CAO system only, $n=9$ ). Although the two groups of participants entered the system by different selection criteria, they have the same learning opportunities, potential experiences and supports during their clinical education. This, therefore, reduces the potentially confounding variables that could influence the outcomes.

\section{Ethical considerations}

Ethical approval was sought and obtained from the Higher Educational Institute where the study was carried out. It was not considered appropriate for the researchers to recruit the students to the study, as they may have felt compelled to participate. For this reason, an independent gatekeeper was asked to inform the students about the study. Ethical issues concerning informed 
consent, anonymity, confidentiality, data generation and handling were considered and upheld. Ground rules were set at the outset of the interviews and upheld throughout.

\section{Data collection and analysis}

Students were assigned to one of two focus group interviews, depending on their method of recruitment into nursing. A total of 23 students attended between the two groups, with more students who had undergone a recruitment selection interview attending. There were much fewer males than females in the class and as a consequence fewer males in attendance at both interviews. For this reason, the researchers agreed not to divulge the exact number of males who attended the interviews in an effort to protect their anonymity. An independent experienced moderator, not known to the student body, facilitated both focus group interviews to ensure equivalence. Prior to the focus group, the moderator and the observer discussed the manner in which the focus groups would be conducted. The interviews lasted between 55-60 minutes. Both interviews were recorded and typed verbatim. Notes were taken by the observer who synopsised the information yielded at the end of the interviews and sought verification from the participants. This helped in establishing the credibility of the study.

A debriefing session was performed at the end of the interviews and no sensitive issues emerged. The researchers advised the students that they could refer them to the Institute's student counselling service in the event of them not wishing to discuss any sensitive issue within the group. Students were also informed that they could contact the researchers directly, should they wish to discuss any issues.

Framework analysis served as the analysis framework (Richie \& Spencer 1994). This process is similar to thematic analysis but is more systematic and has visible stages to the analysis process, which is attractive to readers of research reports. The key stages of familiarisation; identifying a thematic framework; indexing; charting, mapping and interpretation were followed by one of the researchers and then verified by a second researcher. The data were read, analysed and cross-compared by the researchers to ensure that all data were captured and interpreted accurately in the analysis.

\section{Findings}

The three themes which emerged from the analysis of the combined interviews are discussed in this section. The final themes were mutually exclusive and incorporate all the components of the discussion that took place between the two interviews. The quotations presented in the Findings section are representative of a range of interviewees from the two groups.

\section{The caring component}

This theme, as the name implies, refers to the students' perception of nursing, which they associated predominantly with caring. None of the students felt that the media had attracted or deterred them from doing nursing. They did, however, acknowledge the potential impact of the media on society's perception of nursing as a career. Some students had been subjected to comments about nursing from people who were influenced by the media.

The majority of students in both groups felt that they had an innate desire to care for and support people. They, therefore, considered that nursing was the career most suited to them. Without exception, the students felt that they would enjoy the benefits of a career that offered an opportunity to care for and work with people:

At the end of the day you are caring for people and you are seeing them get better.

I know that my sister has also been inspired to do nursing from seeing nurses do their work.

I saw the caring side from them (her family) and they would come home and tell me all their stories. It's such a nice nature.

Some students had gained work experience as care assistants. This experience influenced their perception of what it would be like to work as a nurse. The participants anticipated that caring for people would be 'rewarding':

The good feeling that you get out of nursing people. That would have been the main reason I picked nursing.

I knew I couldn't work in an office with a computer and no human contact. I knew I wouldn't be able to sit behind a desk as well. I'm not sure what made up my mind about nursing. I just decided from then [after work experience] that's what I wanted to do.

Of the 23 students interviewed, it was interesting to note that eight had not selected nursing as their first career choice. Five students would have preferred careers in alternative healthcare professions like physiotherapy, occupational therapy, medicine or radiography. However, they did not achieve sufficient grades in their leaving certificate exams to be accepted onto these courses. The other three students were interested in teaching but did not have sufficient grades in the Irish language to meet the entry criteria. None of these students regretted that they had chosen nursing as an alternative career choice:

I love what I'm in now and would be happy to stay in it but if I had the chance to get into medicine I would definitely take it.

The students felt that exposure to the clinical placements would definitively determine for them whether they had made 
the correct career choice and whether their impressions of nursing were correct in the first instance:

After six weeks you're going to know if the information you have learned to date is working for you and if you're capable of doing the job.

After six weeks you're going to know whether you're in the right place or not.

It (clinical placements) will be the decider I think.

When asked about the work of a nurse, the students felt that they would be very much part of the multidisciplinary team, which they envisaged would operate harmoniously in the hospital setting:

You can't work alone. The nurses, the doctors, the physios - all of them work together for the patient.

They also felt that they would spend considerable time communicating with patients and their families. They associated nursing work with the provision of education and health promotion:

I'm thinking about advocacy. You're the patient's advocate.

You educate the patient on their health and well-being.

...companionship I suppose. The patient could see the nurse as a friend.

All participants concurred that nursing involved caring for people and that the work would be rewarding and fulfilling. While some students had not chosen nursing as their primary career, they too felt that they would enjoy the caring aspect and the human interaction.

\section{Gender issues}

While this theme comprised a small part of the overall study because of the limited number of males interviewed, we consider that it is of interest. The theme is concerned with gender in nursing and the effect of negative connotations associated with male nurses. The students in the group were asked about their perceptions of gender in nursing. There was a general consensus among students that male nurses are not positively accepted in Irish society. The students considered that the general public still regard nursing as a predominantly female profession which is most suited to women:

I thought I should apply for something else ... because I didn't want to have to deal with ... people laughing and stuff.

The male students needed encouragement to pursue a career in nursing. They were positively influenced primarily by family members or by friends. The students felt that those people they had encountered to date in their course had been supportive towards them in their career choice. They voiced concerns about possible negative attitudes towards them during clinical placements. The students linked the perception of nursing as a female career with the influence of the media on society.

\section{The missing link}

This theme is related to the students' perceptions of their nursing course, of which they had completed 10 weeks at the time of interview. The students were surprised at the course content and the mechanism by which the content was delivered. All students could identify with the importance of learning about communication although some found it unusual that communication and caring were a component of the course. The clinical skills component was highly valued and considered to be essential in preparation for clinical placements:

They are telling you things that seem like common sense. You know how to talk to a patient and not to speak over them. It just seems that it's like a bit of common decency and common sense.

I actually think that the communication and caring lectures are really interesting. It is helpful that someone else has done research and backed it up and said that this is the way to do it.

For most students, the contribution of subjects such as physics, psychology and sociology was not acknowledged or recognised. They placed little if any value on pursuing these subjects and many failed to see how there could be a link between them and nursing:

All this psychology and sociology - I didn't know we'd have to do all that. You're sitting there thinking what has all this to do with nursing.

Although 2/3 of it (Behavioural and social science subjects) might not be relevant to me, it might be relevant to someone else. I imagine they have to put it in (to the curriculum) for everyone.

The students were asked whether they could see any possible benefit to these subjects being taught as part of a nursing degree. A few students agreed that there could possibly be some place for them in a nursing curriculum, but not to the extent to which they were included in the course. Most students felt doubtful about the possible contribution of sociology and psychology towards helping patients:

Obviously when someone was coming up with the curriculum they thought that this [sociology \& psychology] would be a good idea.

When people come into nursing they are expecting it to be a lot different.

I don't think they expect to have to sit through all that kind of thing (law, sociology and psychology) (laughter from the floor). 
I didn't realise we had to have so much physics or chemistry either.

At this early stage in their careers, the link between nursing theory and practice was not entirely evident for the students in this study. All students felt that from the very outset of the course, the theoretical component was heavy and that they were over-burdened with course content:

You really don't get a feel for what nursing is like through the lectures. At the moment I am literally completely lost because I don't understand it.

Because we are on (clinical) placement so much it's not like we are in a normal college. We have twelve weeks placement this year. Those twelve weeks would be used for theory in other courses.

In England they have a Degree Programme in Nursing and they work three days a week in the hospital and get two days of theory and they actually work with patients from the first week. That is a better system.

The students felt that their days in college were very long and comparisons were drawn between themselves and students on other courses, such as Arts. They felt that the students enrolled on other courses had more time off and were less pressurised. Concerns were raised about limited time available to search for literature and study. In addition, participants felt that there was potential for students to drop out before allocation to clinical placements because of the academic pressure. Overall, there were no differences between the two groups interviewed except in the number of attendees.

\section{Discussion}

These findings convey to the reader how first year nursing students regarded nursing as a career and their associated concerns prior to their first clinical placement. The students in this study suggested that nursing involved caring and most participants identified that the desire to care for others was one of their primary reasons for choosing nursing as a career. This is consistent with other studies (Manninen 1998, While \& Blackman 1998, Boughn \& Lentini 1999, Hemsley-Brown \& Foskett 1999, Beck 2000, Rheaume et al. 2003). This noteworthy finding emphasises the importance of ensuring that caring is not undervalued and remains the essence of nursing, despite the modern day expanded role of the nurse. However, it is recognised that the delivery of holistic care in nursing is complex and challenging (Peplau 1952, Minick 1995) and may be outside the scope of novice practitioners who are likely to struggle with the concept and complexity of holistic care (Orland-Barak \& Wilhelem 2005). The provision of good and caring role models for nursing students in all clinical settings may help to address this issue. Furthermore, educators have a role in the promotion of caring by endorsing the principle that caring for oneself is congruent with caring for others (Boughn \& Lentini 1999).

While all interviewees in this study portrayed a desire to care for people, $34 \%$ of the participants had not selected nursing as their first choice of career, a finding which is not unique to this study (Hemsley-Brown \& Foskett 1999, Beck 2000). This finding is also relevant to registered nurses in clinical practice, as they are likely to work with students who seek to authenticate their career choice (Yong 1996).

The students in this study did not perceive that the media had influenced their career decision, yet the media has been recognised as having an insidious effect on the development of stereotypes in nursing (Cunningham 1999). The existence of male nurses has only been acknowledged by the media in recent years (Cunningham 1999). The male nurse stereotype is, therefore, less developed than that of the female nurse (Cunningham 1999).

The concern with gender issues in nursing remains prevalent and is widely acknowledged in the literature (Stott 2004, Yam 2004, Keogh \& O'Lynn 2006). The male students in this study were reticent about undertaking a career in nursing for fear of societal degradation. Barriers which contravene the proposition of males being attracted to a career in nursing include historical issues, role strain, automatic sexual orientation classification, the association with female characteristics and anxiety among male nurses in relation to the level of acceptability of use of touch (Bush 1976, London 1987, Keogh \& O’Lynn 2006). Unless addressed, these barriers may impair male nursing students' abilities to complete their undergraduate programmes and/or their socialisation into the profession (Keogh \& O’Lynn 2006).

From an International perspective, male nurses remain a minority group within the nursing profession. According to the Commission on Nursing (1998), Irish male nurses represent only $7 \%$ of the entire nursing profession. This figure is even smaller in the United States where the figure is only 5-6\% (Zysberg \& Berry 2005). However, males occupy $40 \%$ of senior posts in nursing (Millar 1990). This finding reflects the assertion by Rheaume et al. (2003) that more male than female students associate nursing with career potential. Within the Irish context, there has been a recommendation that recruitment initiatives be positively emphasised towards attracting men into general nursing (Commission on Nursing 1998). However, to improve the retention of male nurses once recruited, there is a need for greater awareness and understanding by members of the profession of the barriers that male nurses face and how these barriers have an impact on men in the profession (Evans 2004). This might be achieved through conference presentations and publications. 
The struggle with the academic component of the nursing course is not restricted to the Irish context. Other researchers have identified that nursing students can be dissatisfied with the academic components of their course (Harvey \& McMurray 1997, Vanhanen \& Janhonen 2000, Glossop 2001). The need for a background in science can deter students from considering a career in nursing (Al-Kandari \& Lew 2005) and also poses difficulties for existing nursing students (Harvey \& McMurray 1997, Thornton 1997). McKee (2002) suggests that Irish colleges should follow the example of some universities in the UK who provide additional intensive study programmes prior to entry to the undergraduate nursing programme. This would help to ensure that all students had the same basic knowledge of biological sciences prior to commencing the course, thereby maximising potential recruitment and retention.

The theory-practice gap may be addressed by encouraging HEIs to reflect on both the theoretical and practical content of the programme. Efforts should be made to deliver content at the most meaningful time for students and at an appropriate level. Furthermore, the employment of varied teaching strategies may help students to make the link between theory and practice. The inclusion of clinical staff and course evaluations by students is fundamental to ongoing curriculum development. While it is recognised that lecturers, because of time constraints and their diverse roles, are unable to engage in clinical practice at the bedside, it would be prudent if mechanisms were developed to ensure that lecturers have a realistic impression of the realities of practice and hence what students require theoretically at the various stages of their programme. This could be achieved through partnership schemes such as that of the local joint working group mechanism. This group was instigated to support the development and roll-out of the undergraduate nursing programme in Ireland. The development of initiatives such as that of practice learning teams currently being explored in the UK, is one means by which this might also be addressed. These teams involve a group of nursing practice staff and lecturers who work collaboratively to support student learning in the clinical area (Chapple \& Aston 2004). Another model worth noting is that of the Clinical Teaching Fellow Model (CTFs) which is currently being considered in Australia. This model incorporates the provision of a permanent link between the HEIs and their healthcare partners (Mannix et al. 2006) in an attempt to reduce the theory-practice gap.

\section{Conclusion}

This article explored Irish nursing students' perceptions of nursing as a career before exposure to the first clinical placement. It identified that students recruited into nursing by two different methods had similar perceptions of nursing as a career. The one notable difference between the two groups of participants was that those who had attended for a recruitment interview before starting nursing attended in greater numbers for the focus group interviews after they started the nursing course. The study revealed that prior to clinical placements, nursing is perceived by nursing students as a rewarding career which encompasses a major caring component and being part of the multidisciplinary team. The impact of society and general perceptions of nursing and nurses is somewhat linked with the influences of the media and can vary from being a valued career to being one that does not require independent decision-making abilities. The recruitment of males into nursing remains problematic, which appears not to be assisted by media and social influences. We recommend increasing the awareness and understanding of members of the nursing profession of the barriers facing male nurses and how these barriers impact on men in the profession. This study also found that students continue with the struggle to reconcile the academic component of the nursing course with their perception of what nursing is and should be. We advocate that nurses who act as preceptors to students should be invited to contribute towards curriculum development. This may help to ensure that students have the appropriate theoretical knowledge and skills required prior to their first and subsequent placements.

\section{Limitations}

Despite the inherent value of focus group interviews, we acknowledge the potential for domination by the more vocal participants. In this study, while the moderator tried to include all members of the group in the discussion, the group process could have mitigated against engagement by the quieter participants in the group. However, the moderator was cognisant of this possibility and drew on previous experience to minimise this occurring.

\section{Contributions}

Study design: MM; data collection and analysis: $\mathrm{MM}, \mathrm{MG}$, FOB and manuscript preparation: MM, MG, FOB.

\section{References}

Al-Kandari F \& Lew I (2005) Kuwaiti high school students' perceptions of nursing as a profession: implications for nursing education and practice. Journal of Nursing Education 44, 533-540.

Andrica D (1995) Professional image: what counts? Nursing Economics 13, 375. 
Beck C (2000) The experience of choosing nursing as a career. Journal of Nursing Education 39, 320-322.

Boughn S \& Lentini A (1999) Why do women choose nursing? Journal of Nursing Education 38, 156-161.

Brodie D, Andrews G, Andrews J, Thomas G, Wong J \& Rixon L (2004) Perceptions of nursing: confirmation, change and the student experience. International Journal of Nursing Studies 31, 721-733.

Bush P (1976) The male nurse: a challenge to traditional role identities. Nursing Forum 15, 390-405.

Chapple M \& Aston E (2004) Practice learning teams: a partnership approach to supporting students' clinical learning. Nurse Education in Practice 4, 143-149.

Commission on Nursing (1998) A Report of The Commission on Nursing. A Blueprint for the Future. The Stationary Office, Dublin.

Cook T, Gilmer M \& Bess C (2003) Beginning students' definitions of nursing: an inductive framework of professional identity. Journal of Nursing Education 42, 311-317.

Cunningham A (1999) Nursing stereotypes. Nursing Standard 13, 46-48.

Evans J (2004) Men nurses: a historical and feminist perspective. Journal of Advanced Nursing 47, 321-328.

Glossop C (2001) Student nurse attrition from pre-registration courses: investigating methodological issues. Nurse Education Today 21, 170-180.

Godfrey K (2000) Don't believe the hype. Nursing Times 96, 28-29.

Grainger P \& Bolan C (2006) Perceptions of nursing as a career choice of students in the Baccalaureate nursing program. Nurse Education Today 26, 38-44.

Harvey B \& McMurray N (1997) Students' perceptions of nursing: their relationship to attrition. Journal of Nursing Education 36, 383-389.

Hemsley-Brown L \& Foskett N (1999) Career desirability: young people's perceptions of nursing as a career. Journal of Advanced Nursing 29, 1342-1350.

Hoke J (2006) Promoting nursing as a career choice. Nursing Economics 24, 94-101.

Kennedy A(1999) A problem shared. The World of Irish Nursing July-August, 7, 14-15.

Keogh B \& O’Lynn C(2006) Gender based barriers for male student nurses in general nursing education programs: an Irish perspective. In Men in Nursing: History, Challenges and Opportunities (O’Lynn CE \& Tranbarger RE eds). Springer Publishing Company, New York. pp 193-204.

Kiger A (1993) Accord and discord in students' images of nursing. Journal of Nursing Education 32, 309-317.

Kitzinger J (1994) The methodology of focus groups: the importance of interaction between research participants. Sociology of Health and Illness 16, 105.

Larsen P, McGill J \& Palmer S (2003) Factors influencing career decisions: perspectives of nursing students in three types of programs. Journal of Nursing Education 42, 168-173.

London F (1987) Should men be actively recruited into nursing? Nursing Administration Quarterly 12, 75-81.

Manninen E (1998) Changes in nursing students' perceptions of nursing as they progress through their education. Journal of Advanced Nursing 27, 390-398.

Mannix J, Faga P, Beale B \& Jackson D (2006) Towards sustainable models for clinical education in nursing: an on-going conversation. Nurse Education in Practice 6, 3-11.
May F, Champion V \& Austin J (1991) Public values and beliefs toward nursing as a career. Journal of Nursing Education 30, 303310.

McKee G (2002) Why is biological science difficult for first-year nursing students? Nurse Education Today 22, 251-257.

Meier W (1999) The image of a nurse-myth vs. reality. Nursing Economics 17, 273-275.

Millar B (1990) Wasting women. Nursing Times 86, 21.

Minick P (1995) The power of human caring: early recognition of patient problems. Scholarly Inquiry for Nursing Practice: An International Journal 9, 303-317.

Orland-Barak L \& Wilhelem D (2005) Novices in clinical practice settings: student nurses stories of learning the practice of nursing. Nurse Education Today 25, 455-464.

Peplau H (1952) Interpersonal Relations in Nursing. G.P. Putuam's Sons, New York.

Rheaume A, Woodside R, Gautreau G \& DiTommaso E (2003) Why students choose nursing. Canadian Nurse 99, 25-29.

Richie J \& Spencer L (1994) Qualitative data analysis for applied policy research. In Analysing Qualitative Data (Bryman \& Burgess eds). Routledge, London, pp. 173-194.

Roper N (1976) An image for nursing for the 1970's. Nursing Times 72, 61-64.

Seago J, Spetz J, Alvarado A, Keane D \& Grumbach K (2006) The nursing shortage: is it really about image? Journal of Healthcare Management 51, 96-108.

Spouse J (2000) An impossible dream? Images of nursing held by pre-registration students and their effect on sustaining motivation to become nurses Journal of Advanced Nursing 32, 730-739.

Stott A (2004) Issues in the socialisation process of the male student nurse: implications for retention in undergraduate nursing courses. Nurse Education Today 24, 91-97.

Streubert Speziale H \& Carpenter D (2003) Qualitative Research in Nursing: Advancing the Humanistic Imperative. Lippincott Williams \& Wilkins, Philadelphia.

Thornton T (1997) Attitudes towards the relevance of biological, behavioural and social sciences in nursing education. Journal of Advanced Nursing 26, 180-186.

Vanhanen L \& Janhonen S (2000) Factors associated with students' orientations to nursing. Journal of Advanced Nursing 31, 10541062.

Wells J \& McElwee C (2000) The recruitment crisis in nursing: placing Irish psychiatric nursing in context - a review. Journal of Advanced Nursing 32, 10-18.

While A \& Blackman C (1998) Reflections on nursing as a career choice. Journal of Nursing Management 6, 231-237.

White J, Williams W \& Green B (1999) Discontinuation, leaving reasons and course evaluation comments of students on the common foundation programme. Nurse Education Today 19, 142-150.

Williams B, Wertenberger D \& Gushuliak T (1997) Why students choose nursing. Journal of Nursing Education 36, 346-348.

Yam B (2004) From vocation to profession: the quest for professionalization of nursing. British Journal of Nursing 13, 978-982.

Yong V (1996) 'Doing clinical': the lived experience of nursing students. Contemporary Nurse 5, 73-79.

Zysberg L \& Berry D (2005) Gender and students' vocational choices in entering the field of nursing. Nursing Outlook 53, 193198. 